\title{
Bayesian Classification of Cytochrome P450 3A4 Substrates/Non-substrates and Color Mapping for Chemical Interpretation
}

\author{
Kiyoshi Hasegawa ${ }^{\mathrm{a}}$, Kimito Funatsu ${ }^{\mathrm{b}^{*}}$ \\ ${ }^{a}$ Chugai Pharmaceutical Company, Kamakura Research Laboratories, Kajiwara 200, Kamakura, \\ Kanagawa 247-8530, Japan \\ ${ }^{\mathrm{b}}$ University of Tokyo, Department of Chemical System Engineering, Hongo 7-3-1, Bunkyo-ku, Tokyo \\ 113-8656, Japan
}

(Received January 25, 2010; Accepted April 12, 2010)

Prediction of cytochrome P450 (CYP) 3A4 substrates is valuable for finding promising drug candidates and a considerable amount of attention has been devoted to in silico predictions. Machine learning (ML) methods have recently been explored for perfoming ligand-based approaches. ML methods utilize supervised learning methods such as neural networks, support vector machines and Bayesian approaches to develop statistical models. In this paper, we used Bayesian approach to classify CYP 3A4 substrates and non-substrates. The extended connectivity fingerprint (ECFP) descriptor was used as chemical descriptor. The atom score was calculated from the Bayesian score of each fingerprint. By visualizing the atom scores with five graded-colors, the color mapping for each compound was performed. This can be used for chemical interpretaion why the specific compound exhibits CYP 3A4 substrate. The established Bayesian model and the associated color mapping would be useful for avoiding the risk of CYP 3A4 substrate in early drug discovery. The parallel use of the prediction of oxidation sites in the subsequent paper can give us de novo prediction of any molecules concerning CYP 3A4.

Keywords: Cytochrome P450 substrate, Machine learning, Bayesian approach, Extended connectivity fingerprint, Color mapping

\footnotetext{
*funatsu@chemsys.t.u-tokyo.ac.jp
} 


\section{Introduction}

Modern drug discovery efforts have primarily been focused on the search and optimization of molecules interacting with specific therapeutic target, possessing desirable ADMET (absorption, distribution, metabolism, excretion, and toxicity) properties [1]. So far, concerning specific therapeutic target, quantitative structure-activity relationship (QSAR) studies such as multiple linear regression (MLR) and partial least squares (PLS) have been routinely used for finding the correlation of chemical structures with their inhibitory activities. Resulting QSAR models can be utilized to help guide chemical synthesis [2].

ADMET processes often involve interaction with the associated proteins [3]. For example, the cytochrome P450 (CYP) isoenzymes, such as CYP 3A4, CYP 2D6 and CYP 2C9, are responsible for the metabolism of most drugs. The CYP $3 \mathrm{~A} 4$ is the most important to drug metabolism in human because it metabolizes the majority of commercially available drugs. P-glycoprotein (P-gp) is an ATP-dependent drug efflux pump which can transport a diverse range of structurally and functionally unrelated substrates across the plasma membrane. Over expression of this protein may result in multidrug resistance and is a major cause of the diminished efficacy of drugs. Human ether-a-go-go related gene (hERG) is a responsible protein for cardiac toxicity. Inhibitrion of the hERG channel is shown to potentially lead to prolongation of the interval between the $\mathrm{Q}$ and $\mathrm{T}$ waves in electrocardiograms. This eventually can lead to fatal cardiac arrhythmia.

Prediction of CYP 3A4 substrates is valuable for finding promising drug candidates and a considerable amount of attention has been devoted to in silico predictions [4]. There are mainly two approaches: (1) ligand-based, and (2) structure-based. In silico modeling based on the protein structure seems to be the promising approach thanks to the increase of the X-ray crystal structures of human CYPs. While there is no question about the value of the information those crystal structures provide, a limitation of structure-based approach also became clear. The structures of CYP 3A4 show large cavities, large enough to bind multiple ligands simultanesouly. Therefore, the docking approach will have a limitation in studying such flexible structures. Understanding the intractions between the ligand and the protein requires multiple structures of ligand-CYP complexes [5].

Machine learning (ML) methods have recently been explored for perfoming ligand-based approaches [3]. ML methods utilize supervised learning methods such as neural networks, support vector machines and Bayesian approaches to develop statistical models capable of predicting more diverse spectrum of structures and ADMET properties than those described by the available QSAR models. These features make ML methods attractive for developing alternative virtual screening tools to complement structure-based and ligand-based methods.

In this paper, we used Bayesian approach to classify CYP 3A4 substrates and non-substrates. The extended connectivity fingerprint (ECFP) descriptor was used as chemical descriptor. The atom score was calculated from the Bayesian score of each fingerprint. By visualizing the atom scores with five graded-colors, the color mapping for each compound was performed. This can be used for chemical interpretaion why the specific compound exhibits CYP 3A4 substrate. The established Bayesian model and the associated color mapping would be useful for avoiding the risk of CYP 3A4 substrate in early drug discovery. The parallel use of the prediction of oxidation sites in the subsequent paper can give us de novo prediction of any molecules concerning CYP 3A4.

\section{Material and Methods}

\subsection{Data set}

In this study, the data set of CYP $3 \mathrm{~A} 4$ substrates and non-substrates was taken from the literature [6]. 'Bortezomib' was omitted from the data set because this is only compound bearing the boron atom. According to the literature [6], we divided whole data set into the training and test sets. The separation of the training and test sets was performed taking considerations of their distribution in the chemical space. The total number of substrates and non-substrates are 311 and 289 in the training set, respectively. The total number of substrates and non-substrates are 56 and 44 in the test set, respectively. Also, we performed another external test validation with chemical structures in the subsequent paper [7]. In the subsequent paper, their oxidation sites toward CYP 3A4 were well predicted using several ML methods [7]. All of these compounds are known to be CYP 3A4 substrates. The number of compounds in the external validation set is 61 .

\subsection{Bayesian classifier}

Model was built by Bayesian classifier as implemented in Pipeline Pilot. ECFP_6 (extended connectivity fingerprints with path-lengths of 6) was calculated in Pipeline Pilot and it was used as chemical descriptor [8]. In this study, FCFP (functional class fingerprint) was not 
used because ECFP can describe chemical structures in more details and it is suitable for calculating the atom scores described in the next section [9]. A Bayesian classifier compares the frequency of occurrences of descriptors that are found in two groups that discriminate best between these groups (substrates vs non-substrates) $[10,11]$. In order to improve the capability of prediction, a post-processing step was performed to remove low-information ECFP 6 bins. Low-information bins are those that have normalized estimates in the range of -0.05 and 0.05 .

The Bayesian method offers three important features $[10,11]$ : First, it is fast and efficient for large data sets, scaling linearly with respect to the number of molecules. This is owing to that data frequency statistics are collected and frequency themselves become the model. Second, because the method is not a fitting method, it is less affected by the course dimensionality when large number of descriptors are used. This nature also aides in modeling imbalanced data sets. Third, the Bayesian model weights features by assigning greater significance to characteristics that appear to distinguish substrates from baseline compounds. This is in contrast to the static distance functions used by clustering methods, such as the Tanimoto distance between two fingerprints, in which all bits are given equal weight.

The use of Bayesian classifier allows us to apply their fragment mining method to identify substructures frequently found in substrate and non-substrate compounds. The ECFP_6 most associated with substrate or non-substrate compounds was translated into $2 \mathrm{D}$ substructure within Pipeline Pilot.

\subsection{Atom score and its visualization}

The atom scoring is a method to calculate score for each atom in molecule based on Bayesian scores [12]. First, a Bayesian model was built and the corresponding ECFP 6 substructure was scored and categorized as substrate or non-substrate features. Each substructure's score was divided by the number of heavy atoms and the calculated scores were assigned on atoms in each substructure. Then, the substructures of test molecule were identified, and the respective scores for each atom in the substructure were summed up and divided by the number of frequency occurence to calculate their averaged atom scores. The schematic illustration is shown in Figure 1. The example is 'Dutasteride' containing the amide fragment.

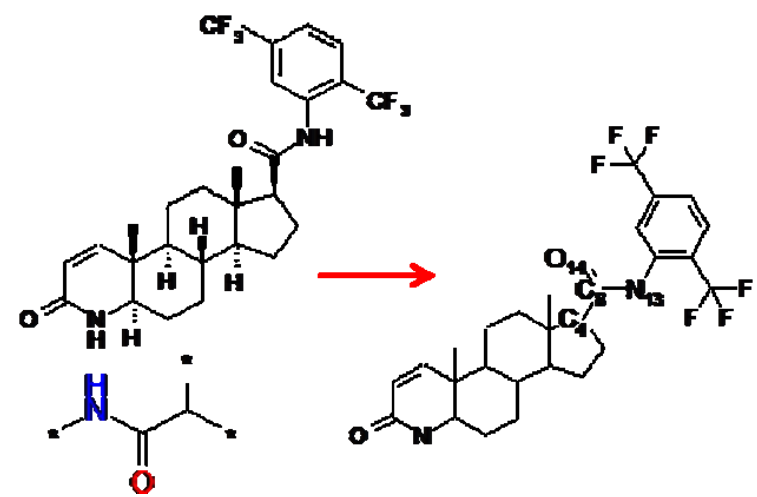

Atom4 $C+=$ Atom Score
Atom $C+=$ Atom Score
Atom13N+= AtomScore
Atom14O+m Atom Score

Figure 1 Schematic illustration for calculating atom scores with example 'Dutasteride'

Four thresholds were used to color atoms in five graded-colors $(0.02,0.01,-0.01$, and -0.02$)$. The atom coloring scheme is blue for best atom, green for good, black for marginal, yellow for bad and red for worst. Data records with known substrate (positive) and non-substrate (negative) molecules are piped into a component, Bayesian model builder, in Pipeline Pilot. Fragment SMARTS and their corresponding fingerprint bin values are stored in a text file. Then, the learned model with model fragment scores is loaded and "joined" the text file to correlate scores and fragment SMARTS, and the scores are divided by the number of heavy atoms to calculate the atom scores.

\section{Results and Discussion}

The Bayesian model of 600 CYP 3A4 compounds was constructed through Pipeline Pilot. The model can provide 12595 unique bins for ECFP 6 substructures. The base-line value separating between substrates and non-substrates is -0.819 . Therefore, if the score of compound is greater than this value, the compound is predicted to be substrate. Others, the compound is predicted to be non-substrate. The recognition rates of substrates and non-substrates in the training set are 285/311 (92\%) and 280/289 (97\%), respectively. The recognition rates of substrates and non-substrates in the test set are 47/56 (84\%) and 37/44 (84\%), respectively. The performance of the Bayesian model is well tolerated for further prediction. The established model was applied to the CYP 3A4 substrate compounds derived from the subsequent paper [7]. The prediction rate is $53 / 61(87 \%)$. The prediction results of two external validations are high enough to use as a prediction filter in early stage of drug discovery. Best five significant fragments are shown in Figure 2. In substrate fragments, tertiary $\mathrm{N}$ 
atoms are often identified. On the other hand, in non-substrate fragments, carboxylic acids are often identified. This fragments list might be useful for chemical interpretation. However, the description is a little bit ambious and other approcah is required to refine the description. We got an idea whether the scoring value of each fragment can be breaking dowin into the atomic level and this detailed information can be used for chemical interpretation.
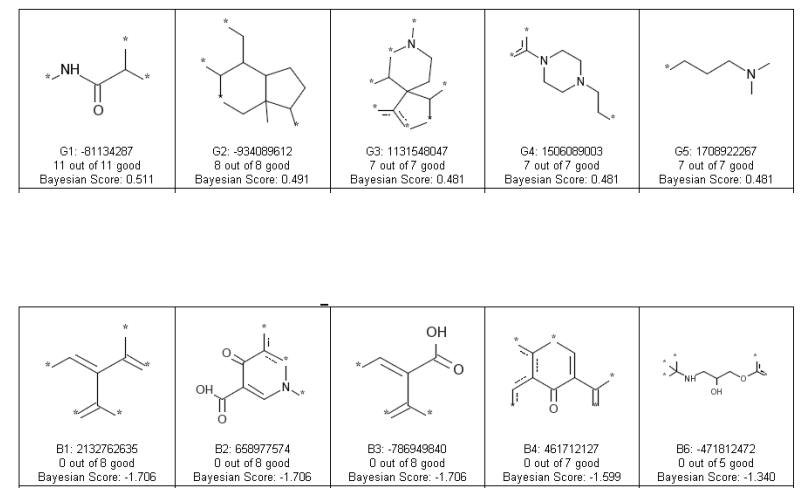

Figure 2 Best five significant fragments. Index number, frequency occurrence and Bayesian score are included in each box. (Top: substrate fragments, Low: non-substrate fragments)

We developed the scheme for calculating atom scores according to the algorithm in the previous section. The saved file for atom scores was used to make atom-coloring to test compound. For medicinal chemists, we constructed web application page. The example is shown in Figure 3. Two input formats are available: one is ISIS/Draw and other is SDF formats. Medicinal chemists sketch own structure via ISIS/Draw and perform copy/paste to the specific JAVA window. When putting the submit button, the result with atom-colorings is displayed in the first column. In the second column, the Bayesian score is displayed. In the third column, the result of classification whether the input molecule is CYP 3A4 substrate or non-substrate is displayed. In the fourth column, medicinal chemists can see the nearest chemical structure to the input molecule, which is included in the training set. This information is very important because the prediction confidence on the compound beyond chemical space in the training set is considered to be not reliable. The value of 0.5 in Tanimoto similarity is the threshold for judging the application domain [13].

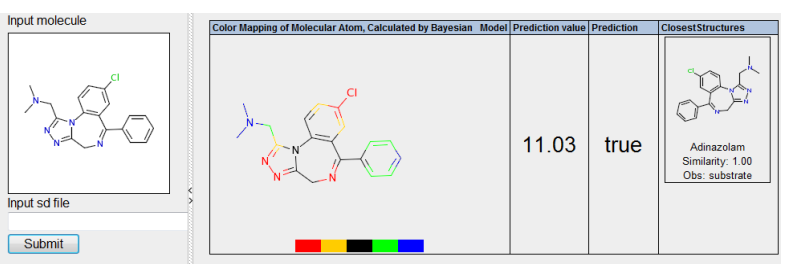

Figure 3 Web application page for atom-coloring (Example: 'Adinazolam')

The representative examples of atom-coloring are shown in Figure 4. In this figure, blue colors mean the liable atoms against CYP 3A4. As for 'Adinazolam', the tertiary $\mathrm{N}$ atom is identified to be liable atom. As for 'Clarithromycin', the tertiary $\mathrm{N}$ atom and ethyl substituent on the macrocyclic ring are identified to be liable atoms. The predictions exactly match with the experimental results. So, medicinal chemists can get any new ideas how to avoid the risk factors using this atom-coloring map. Previously, other researchers have proposed the similar approach for atom-coloring on CYP substrates [14]. However, their approach is quite complicated and anyone cannot reproduce the same result. Our approach is quite simple and it can be extended to other ADMET issues such as P-gp substrates and hERG inhibitors. Furthermore, our approach can be applicable to any local models, which are constructed from many derivatives with the fixed core structure. Actually, we are planning to analyze the inhibitory activities against multiple proteins by Bayesian approach and the key features for selectivity are successfully identified by the atom-coloring scheme.
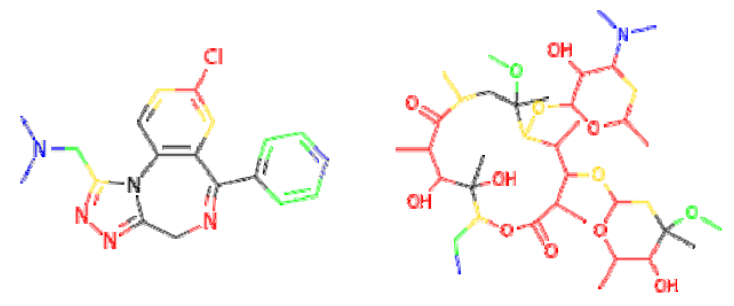

Figure 4 Test molecules with atom-coloring (Examples: 'Adinazolam' and 'Clarithromycin')

\section{Conclusion}

In this paper, we used Bayesian approach to classify 
CYP 3A4 substrates and non-substarats. The fingerprint descriptor was used as chemical descriptor. By using Bayesian score for each fingerprint, we calculated the atom scores and visualized the atom-coloring mapping for chemical interpretaion. Our approach can be extended to other ADMET issues such as P-gp substrates and hERG inhibitors. Furthermore, our approach can be applicable to any local models, which are constructed from many derivatives with the fixed core structure. The parallel use of the prediction of oxidation sites in the subsequent paper can give us de novo prediction of any molecules about CYP 3A4.

\section{Acknowledgement}

We thank to Dr. Ishizaki at Accerlys Japan Co., Ltd. for scientific assistance.

\section{References}

[1] K. Hasegawa, K. Funatsu, in Frontiers in Drug Design and Discovery, Vol. 4 (Ed: W.C. Gary), Bentham Science Publishers, 2009, pp. 378-428)).

[2] K. Hasegawa, K. Funatsu, in Chemoinformatics and Advanced Machine Learning Perspectives:

Complex Computational Methods and Collaborative
Techniques (Eds: H. Lodhi, Y. Yamanishi), IGI publishing 2010, in press.

[3] H. Li, C.W. Yap, C.Y. Ung, Y. Xue, Z.R. Li, L.Y. Han, H.H. Lin, Y.Z. Chen, J.Pharm.Sci., 2007, 96, 2838-2860.

[4] R. Arimoto, Curr.Top.Med.Chem., 2006, 6, 1609-1618.

[5] S. Ekins, D.M. Stresser, J.A. Williams, Trends.Pharm.Sci., 2003, 24, 161-166.

[6] C.W. Yap, Y.Z. Chen, J.Chem.Inf.Model., 2005, 45, 982-992.

[7] K. Hasegawa, M. Koyama, K. Funatsu, Mol.Inf., 2010, 29, 243-249.

[8] Pipeline Pilot Basic Chemistry Component Collection, Accelrys, Inc. 10188 Telesis Court, Suite 100, San Diego, CA 92121, USA.

[9] Y. Hu, R. Unwalla, R.A. Denny, J. Bikker, L. Di, C. Humblet, J.Comput.Aided Mol.Des., 2010, 24, 23-35.

[10] X. Xia, E. Maliski, P. Gallant, D. Rogers, J.Med.Chem., 2004, 47, 4463-4470.

[11] P. Prathipati, N.L. Ma, T.H. Keller, J.Chem.Inf.Model., 2008, 17, 2362-2370.

[12] J.T. Metz, D.A. Stonich, D. Rogers, Visualization of Atomic Contributions to Ligand Properties, SciTegic Users Group Meeting 2007.

[13] D.G. Sprous, J.Mol.Graph.Model., 2008, 27, 225-232.

[14] S. Boyer, C.H. Arnby, L. Carlsson, J. Smith, V. Stein, R.C. Glen, J.Chem.Inf.Model., 2007, 47, 583-590. 


\title{
Cytochrome P450 3A4に対する基質/非基質のベイズ分類と 化学的解釈のためのカラーマッピング
}

\author{
長谷川 清、船津 公人 ${ }^{\text {* }}$ \\ ${ }^{a}$ 中外製薬株式会社・鎌倉研究所（广247-8530 神奈川県鎌倉市梶原200番地） \\ ${ }^{b}$ 東京大学大学院工学系研究科（ $\bar{T} 113-8656$ 東京都文京区本郷7-3-1）
}

Cytochrome P450 3A4に対する基質予測は、候補医薬品を探索する際に重要であり、これまでin silico 予測として注目されてきている。最近、ligand-based 手法として、学習機械 (Machine learning: ML) が、利用されている。MLは、ニューラルネットワーク、サポートベクトルマシー ン、ベイズ法のような統計モデルを構築する教師つき学習法である。本研究では、Cytochrome P450 3A4に対する基質と非基質を分類するために、ベイズ法を用いた。構造記述子として、 extended connectivity fingerprint (ECFP)を用いた。それぞれのfingerprintのベイズスコアから、ア トムスコアを計算した。アトムスコアを 5 段階に彩色することで、化合物のカラーマッピング を行った。これにより、特定の化合物がどうして、CYP 3A4基質になるかという化学的解釈が 可能となる。したがって、ベイズモデルとカラーマッピングにより創薬の初期段階でCYP $3 \mathrm{~A} 4$ 基質のリスクを避けることが可能となった。先に開発した代謝部位予測と併用すれば、CYP 3A4 に関して、任意の化合物の de novo 予測が可能となる。

キーワード: Cytochrome P450、学習機械、ベイズ法、Extended connectivity fingerprint、 カラーマッピング

\footnotetext{
*funatsu@chemsys.t.u-tokyo.ac.jp
} 